\title{
Induction of $\mathrm{H} 3.3$ replacement histone mRNAs during the precommitment period of murine erythroleukemia cell differentiation
}

\author{
Dora B.Krimer ${ }^{+}$, Genhong Cheng ${ }^{\S}$ and Arthur I.Skoultchi* \\ Department of Cell Biology, Albert Einstein College of Medicine, 1300 Morris Park Avenue, Bronx, \\ NY 10461, USA
}

Received March 2, 1993; Revised and Accepted May 12, 1993

\begin{abstract}
Differential hybridization to a cDNA library made from the mRNA of differentiating mouse erythroleukemia (MEL) cells has been used to identify sequences that are induced during the early stages of MEL cell differentiation. One of the differentially expressed genes identified encodes the H3.3 histone subtype. We show here that the three polyadenylated mRNAs produced from the H3.3B gene, as well as the single mRNA produced from the related H3.3A gene, are coordinately induced during the first few hours of MEL cell differentiation and subsequently down regulated as cells undergo terminal differentiation. Nuclear runon transcription experiments indicate that the accumulation and decay of these mRNAs are controlled at the post-transcriptional level. Unlike the polyadenylated mRNAs of two $\mathrm{H} 1$ histone genes that exhibit similar kinetics of induction and decay controlled by c-myc, induction of the H3.3 mRNAs is unaffected by deregulated expression of c-myc.
\end{abstract}

\section{INTRODUCTION}

Murine erythroleukemia (MEL) cell lines are transformed erythroid precursors that are blocked at the proerythroblast stage of erythroid maturation (1). A large number of chemical compounds, including hexamethylenebisacetamide (HMBA), can induce these cells to overcome the block and reinitiate the erythroid differentiation program (2). A precommitment period of 12-24 hours is required before cells begin to become irreversibly committed to terminal differentiation $(3,4)$.

During the process of induced differentiation, a number of specific gene expression changes occur. Globin gene expression is markedly increased as MEL cells undergo erythroid differentiation. The large increase in the level of globin mRNA is primarily due to an increase in gene transcription $(5,6)$. The expression of several protooncogenes is also changed after exposure to inducers of differentiation $(7,8,9)$. c-myc and c-myb are expressed in untreated MEL cells. Expression of both genes is down regulated during the first hours of induced differentiation followed by a transient reexpression, approximately 18 hours later, and a subsequent final decline (7, $8,10)$. We have recently described two $\mathrm{H} 1$ histone genes, $\mathrm{H} 1^{\circ}$ and H1var.1, that encode polyadenylated mRNAs that are induced in the early precommitment period (11).

While the changes in gene expression observed during the later stages of MEL cell differentiation (e.g. globin mRNA induction) are related to the differentiation process per se, genes that change their expression level during the precommitment period could be responsible for causing these cells to reenter the erythropoietic program. MEL cell differentiation is thought to be a multistep process (12), in which a cascade of gene expression changes leads to events that trigger expression of other cell type-specific genes. Several lines of evidence suggest that c-myc and c-myb play a critical role in the commitment of the cells to reenter the differentiation program. In particular, MEL cell transfectants in which either c-myc or c-myb are constitutively expressed from heterologous promoters lose the capacity to differentiate $(9,13$, $14,15,16)$. Consistent with the model for a cascade of gene expression changes we have recently shown that deregulation of c-myc but not c-myb interferes with the induction of the two $\mathrm{H} 1$ histone genes that is normally triggered by HMBA treatment (11).

We are interested in the isolation and characterization of genes that may play a role in the initiation of the MEL cell differentiation program. Changes in gene expression during the precommitment stage is one putative characteristic of genes involved in the initial cellular response to an inducer. To identify genes that change their pattern of expression during the early stages of MEL cell differentiation, we screened an HMBAinduced MEL cell cDNA library by differential hybridization. We report here on the changes in the expression level of one of the differentially expressed genes that was identified as the histone subtype H3.3. The H3.3 gene belongs to a group of replication-independent basal histones that are transcribed throughout the cell cycle, usually at low levels (17). In mice and

\footnotetext{
* To whom correspondence should be addressed

Present addresses: ${ }^{+}$Centro de Investigaciones Biológicas, CSIC, Velázquez, 144, 28006 Madrid, Spain and ${ }^{\S}$ Rockefeller University, New York, NY, USA
} 
in other vertebrates, there are two types of $\mathrm{H} 3.3$ genes $(18,19$, 20). The two genes encode identical proteins but they differ in the $5^{\prime}$ and $3^{\prime}$ nontranslated regions. Unlike most histone genes, the H3.3 genes produce polyadenylated mRNAs. We show here that the H3.3A and H3.3B mRNA levels change during MEL cell differentiation, primarily due to post-transcriptional regulation. The expression of both subtypes in different tissues and at different stages of development is also reported.

\section{MATERIALS AND METHODS}

\section{Cell culture}

MEL cell line DS19 was grown in Dulbecco's Modified Eagle's medium (DME) supplemented with 10\% fetal bovine serum. Cultures were induced by the addition of HMBA to a final concentration of $5 \mathrm{mM}$ as previously described (10). Induction was monitored by the benzidine staining reaction. Deregulated c-myc MEL cell transfectants kindly provided by Dr W.Kuehl (9), were grown in RPMI 1640 medium containing $10 \%$ fetal bovine serum. Deregulated c-myb transfectants, a gift from Dr E.Prochownik (13), were grown in DME medium with $10 \%$ fetal bovine serum.

\section{Differential plaque hybridization}

To isolate differentially expressed cDNA clones, we screened a $\lambda t 10-c D N A$ library constructed from polyadenylated RNA extracted from MEL cells that had been induced with HMBA for 18 hours. The preparation of this library has been described previously (11). The cDNA library was plated at low density (600-800 plaques per $150 \mathrm{~mm}$ plate) and screened by a modification of the Benton and Davis procedure (21). Quadruplicate nitrocellulose filters were sequentially imprinted on agar plates for 1, 2, 4 and 8 minutes, respectively. After alkali denaturation, the filters were neutralized and baked at $80^{\circ} \mathrm{C}$ under vacuum for 2 hours. Filters were washed in $1 \mathrm{M} \mathrm{NaCl}, 50 \mathrm{mM}$ Tris $-\mathrm{HCl} \mathrm{pH} \mathrm{7.6,1mM} \mathrm{EDTA} \mathrm{and} 0.1 \%$ SDS for one hour at $42^{\circ} \mathrm{C}$, and prehybridyzed in $5 \times$ SSC, $5 \times$ Denhardt's solution, $50 \mathrm{mM}$ sodium phosphate (pH 6.8), $0.1 \%$ SDS and $100 \mu \mathrm{g} / \mathrm{ml}$ of denatured salmon sperm DNA for four hours at $65^{\circ} \mathrm{C}$. Hybridization was carried out in the same solution containing ${ }^{32} \mathrm{P}$-labeled cDNA probes at $2 \times 10^{6} \mathrm{cpm} / \mathrm{ml}$ for 48 hours.

Complex cDNA probes were prepared from uninduced and induced cell poly A+ RNA with reverse transcriptase (Life Sciences) using conditions specified by the manufacturer. Specific activities of the probes were about $2 \times 10^{8} \mathrm{cpm} / \mu \mathrm{g}$. Differentially hybridizing plaques were picked and purified through second and third rounds of screening employing the same hybridization conditions. The cDNA inserts from the purified clones were prepared by EcoRI digestion of phage DNA and purified by agarose gel electrophoresis and electroelution.

\section{RNA isolation and Northern blot analysis}

Total cellular RNA from MEL cells was prepared by the hot phenol extraction procedure (22). $15 \mu \mathrm{g}$ of total RNA were analyzed by Northern blot hybridization as previously described (11). RNA samples were hybridized with ${ }^{32} \mathrm{P}$ radioactive probes prepared by random priming (Pharmacia) of DNA fragments purified from agarose gels by electroelution. The specific activities of all probes used was approximately $10^{8} \mathrm{cpm} / \mathrm{mg}$. The relative level of mRNAs detected on Northern blots was quantitated by densitometric scanning of autoradiograms with an
Apple Color One Scanner and analysis of data using the Image v.1.47 software.

\section{Nuclear run-on transcription analysis}

Nuclei from uninduced and induced MEL cells were isolated essentially as described previously (6). Briefly, cells were collected by centrifugation, washed with homogenization buffer (0.3M sucrose, $10 \mathrm{mM}$ Tris - $\mathrm{HCl}, \mathrm{pH} 7.4,2 \mathrm{mM} \mathrm{MgOAc}, 3 \mathrm{mM}$ $\mathrm{CaCl}_{2}, 10 \mathrm{mM}$ beta-mercaptoethanol) and lysed by the addition of NP-40 to a final concentration of $0.3 \%$. After centrifugation through $0.6 \mathrm{M}$ sucrose, $10 \mathrm{mM}$ Tris- $\mathrm{HCl} \mathrm{pH} 7.4,5 \mathrm{mM} \mathrm{MgCl}$ the nuclear pellet was resuspend in $50 \mathrm{mM}$ Tris $-\mathrm{HCl}, \mathrm{pH} 7.9$, $25 \%$ glycerol, $0.1 \mathrm{mM}$ EDTA, $10 \mathrm{mM}$ beta-mercaptoethanol, $5 \mathrm{mM} \mathrm{MgCl} 2$ and frozen in liquid nitrogen. In vitro transcription reactions were incubated at $25^{\circ} \mathrm{C}$ for 30 minutes in $50 \mathrm{mM}$ Tris- $\mathrm{HCl} \mathrm{pH} 7.9,5 \mathrm{mM} \mathrm{MgCl}, 1 \mathrm{mM} \mathrm{MnCl}, 1 \mathrm{mM}$ DTT, $0.15 \mathrm{M} \mathrm{KCl}, 0.67 \mathrm{mM}$ of each ATP, GTP and CTP, $2.2 \mu \mathrm{M}$ UTP and $0.2 \mathrm{mCi}$ alpha- ${ }^{32} \mathrm{P}-\mathrm{UTP}(3000 \mathrm{Ci} / \mathrm{mmol})$. Incubation was terminated by addition of SDS to $0.5 \%$ final concentration and $5 \mathrm{ml}$ of $0.1 \mathrm{M} \mathrm{NaOAc}$ pH 5.2, $1 \mathrm{mM}$ EDTA was added. Nuclear RNA was extracted by the hot phenol method, precipitated by ethanol and washed with cold $10 \%$ trichloroacetic acid. A 10 $\mu \mathrm{g}$ sample of each denatured plasmid DNA was transferred to nitrocellulose filters using a Schleicher and Schuell slot blotter. Filters were rinsed in $6 \times \mathrm{SSC}$ and baked at $80^{\circ} \mathrm{C}$ for 2 hours under vacuum. Prehybridization was performed for 4 hours at $42^{\circ} \mathrm{C}$ in $50 \%$ formamide, $5 \times \mathrm{SSC}, 50 \mathrm{mM}$ sodium phosphate buffer $\mathrm{pH} 6.5,1 \times$ Denhardt, $0.1 \%$ SDS, $100 \mu \mathrm{g} / \mathrm{ml}$ denatured salmon sperm DNA. The in vitro labelled run-on transcription products were then added and the hybridization was performed under the same conditions for $\mathbf{4 8}$ hours. The nitrocellulose strips were then washed twice at $60^{\circ} \mathrm{C}$ for 30 minutes in $2 \times \mathrm{SSC}, 0.1 \%$ SDS and in $0.1 \times$ SSC, $0.1 \%$ SDS, treated with $20 \mathrm{mg} / \mathrm{ml} \mathrm{RNase}$ A at $37^{\circ} \mathrm{C}$ for 15 minutes, and finally washed with $2 \times$ SSC for 15 minutes at room temperature.

\section{DNA clones}

pRAH3-2 is a mouse H3.2 genomic subclone that contains a 210 bp insert from the coding sequence including amino acids 56 to 128 (23). pMH921 is a mouse $\mathrm{H} 3.3 \mathrm{~A}$ genomic pseudogene kindly provided by Dr W.Marzluff that contains a $2.6 \mathrm{~kb}$ Hind III fragment subcloned into pUC9 (24). pMH3B-3' is a cDNA clone containing the $3^{\prime}$ non-coding region of the H3.3B mRNA from positions +476 to +1471 of the previously reported sequence (20) and subcloned into pSKM13 + Bluescript plasmid vector (Stratagene). pMH3A-3' contains a 450 bp Kpn I-Hind III fragment from the 3' non-coding region of pMH921 subcloned into pGEM 3Z plasmid vector (Promega).

\section{RESULTS}

\section{Isolation of a histone H3.3 cDNA clone by differential hybridization}

To identify genes that are up-regulated during the precommitment period of MEL cell differentiation, we screened a $\lambda$ gt10-cDNA library that was prepared using poly A+ mRNA isolated from MEL cells that had been treated with HMBA for 18 hours. For MEL cell line DS19, cells that are irreversibly committed for differentiation first begin to appear after about 18-24 hours of HMBA treatment (10). The library was hybridized with complex 


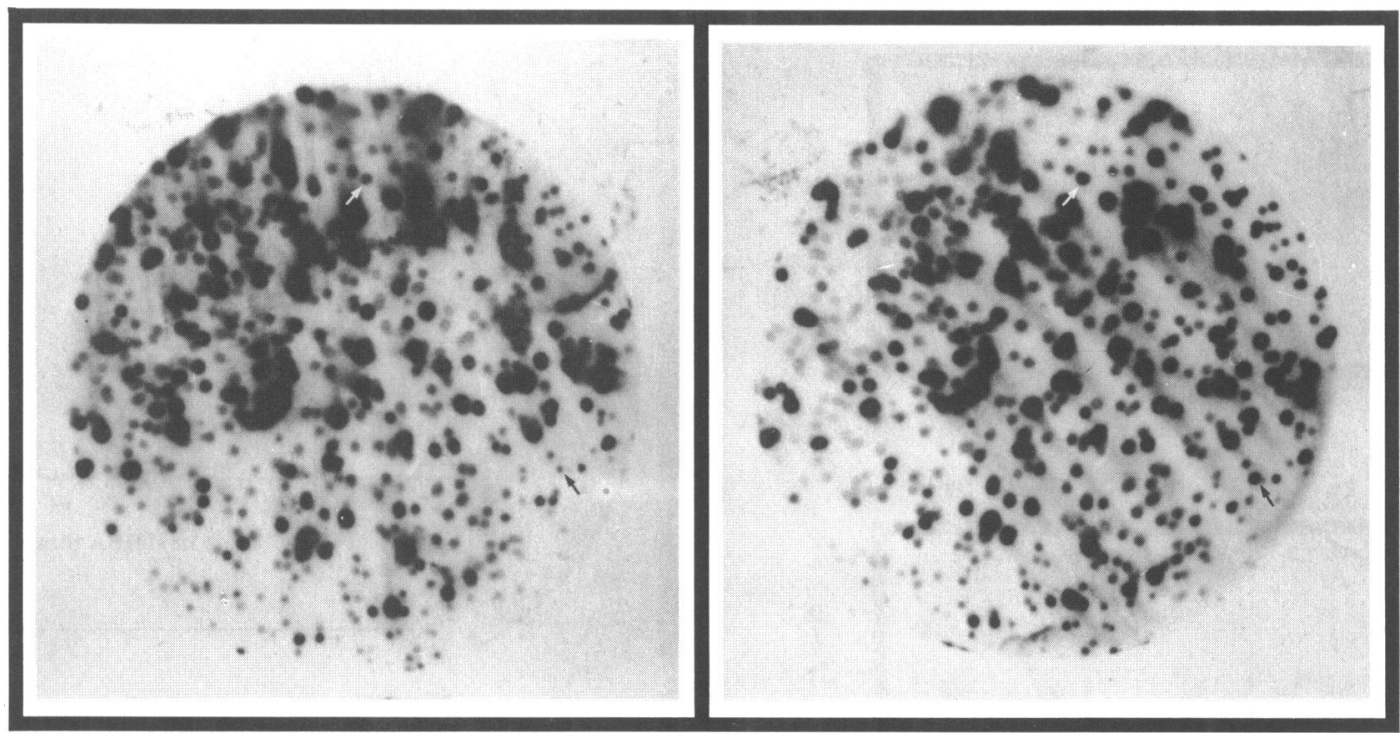

Figure 1. Identification of upregulated genes in HMBA-treated MEL cells by differential hybridization. Primary screening replicas of nitrocellulose filters from a plate of the $\lambda$ gt $10 \mathrm{cDNA}$ library were hybridized with equal amounts of ${ }^{32} \mathrm{P}$-cDNA probes prepared from poly A+ RNA isolated from untreated cells (Uninduced probe) or cells treated with HMBA for 18 hours (HMBA-induced probe). The autoradiograms shown are from the first (uninduced) and second (HMBA-induced) lifts from a series of 4 consecutive replicas (see Methods). Arrows point to two hybridizing plaques showing different intensities with the two probes. White arrows indicate clone 4.2 ; black arrows denote clone 4.1 .

cDNA probes that were synthesized using poly $A+$ mRNA isolated from untreated and HMBA-treated (18 hrs.) cells.

Four filter replicas were prepared from each of several 150 mm plates containing 600-800 plaques per plate. The first and third filters were hybridized with cDNA probe prepared from untreated cells while the second and fourth filters were hybridized with probe prepared from HMBA-treated cells. Using duplicate filters for each probe eliminated some false positives and reduced the number of clones that required secondary screening. Initially about 5,000 plaques were analyzed in this way and after 2 rounds of purification we isolated two clones that appeared to exhibit increased expression in HMBA-treated cells. Figure 1 shows autoradiograms of the first and second filter replicas that were hybridized with probes prepared from untreated and HMBAtreated cells. Two cDNA clones that showed stronger hybridization signals with probe made from HMBA-treated cells were detected (indicated by arrows in Fig. 1). These clones were designated 4.1 and 4.2 .

After two rounds of purification, Northern blot hybridization of total RNA isolated from MEL cells that were treated with HMBA for different periods of time, confirmed increased expression of the two genes. Clone 4.2 hybridized to four RNAs species ranging in size from $0.6-1.8 \mathrm{~kb}$ (Figure 2). The relative amount of three of the RNAs $(1.0,1.2$, and $1.8 \mathrm{~kb})$ increased by 4 hours of HMBA treatment while the amount of the smallest $0.6 \mathrm{~kb}$ RNA species decreased slightly in this period. After subcloning the $800 \mathrm{bp}$ insert of clone 4.2 , we sequenced it from both ends by the dideoxy method and compared the data with sequences registered in the GenBank. The results showed that the insert in clone 4.2 was a cDNA of a histone $\mathrm{H} 3.3$ gene. As discussed below and demonstrated in Figures 3 and 4 in which $\mathrm{H} 3.3 \mathrm{~A}$ and $\mathrm{H} 3.3 \mathrm{~B}$ gene specific probes were used, the 1.8 and

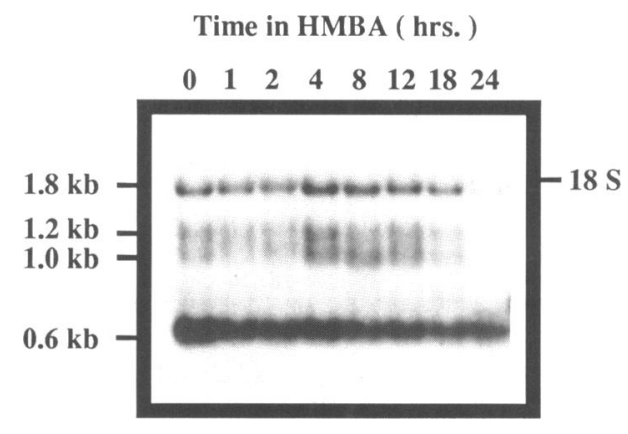

Figure 2. Northern blot hybridization of transcripts in differentiating MEL cells with clone $4.2 \mathrm{cDNA}$ probe. $15 \mu \mathrm{g}$ of total RNA isolated from untreated MEL cells or cells treated with HMBA for the indicated times were analyzed by blot hybridization using the electroeluted Eco RI insert of clone 4.2 as a probe. The position of the 18S rRNA marker, visualized in the gel by ethidium bromide staining, is indicated at the right. Numbers at the left of the figure indicate the estimated sizes of the hybridizing transcripts.

1.0kb hybridizing bands were derived from the $\mathrm{H} 3.3 \mathrm{~B}$ gene, the $1.2 \mathrm{~kb}$ band represents a combination of transcripts from the $\mathrm{H} 3.3 \mathrm{~B}$ and $\mathrm{H} 3.3 \mathrm{~A}$ genes, and the $0.6 \mathrm{~kb}$ RNA represents crosshybridizing replication-dependent $\mathrm{H} 3 \mathrm{mRNAs}$. Clone 4.1 was identified as an alpha-globin cDNA and was not further analyzed.

Expression of both subtypes of histone H3.3 mRNA is increased during early stages of MEL cell differentiation

In vertebrates, there are two classes of $\mathrm{H} 3$ histone proteins: the replication-dependent variants that are expressed coordinately with DNA replication (i.e., H3.1, H3.2) and the replicationindependent variant or basal histone $\mathrm{H} 3.3$, which is expressed 
Time in HMBA ( hrs. )

$\begin{array}{lllllllllllll}0 & 1 & 2 & 4 & 8 & 12 & 18 & 24 & 36 & 48 & 72 & 96\end{array}$

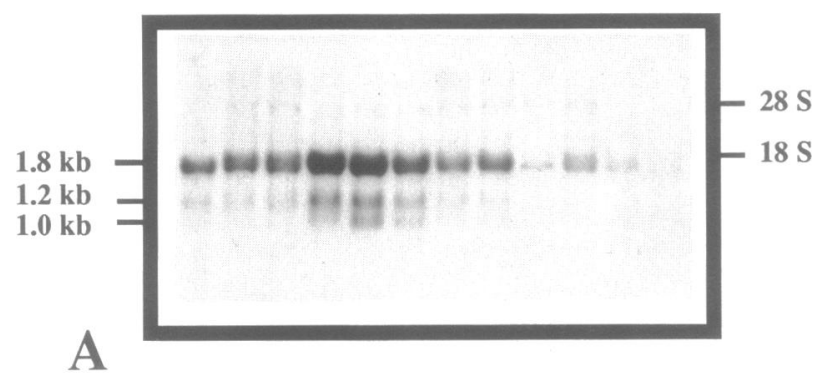

$\begin{array}{llllllllll}0 & 1 & 2 & 4 & 8 & 12 & 24 & 36 & 72 & 96\end{array}$

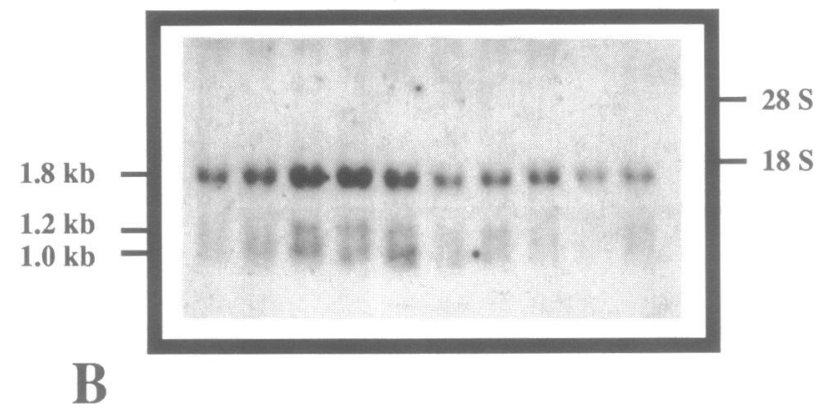

Figure 3. Analysis of H3.3B transcripts in MEL cells using 3' noncoding region probes. $15 \mu \mathrm{g}$ of total RNA isolated from untreated or HMBA-treated MEL cells were hybridized with: A) pMH3B-3', a plasmid containing nucleotides 476 to 1471 of the $3^{\prime}$ noncoding region of the H3.3B cDNA; B) a 20 bp oligomer, GTTGAAGCGGTTTTTATGG, corresponding to the antisense strand of the H3.3B gene in the region immediately after the termination codon.

Time in HMBA ( hrs. )

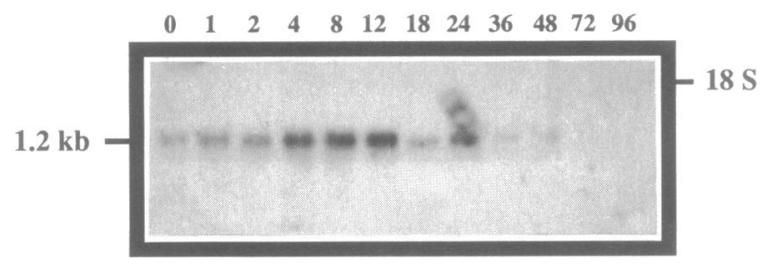

Figure 4. Northern blot hybridization of H3.3A mRNA in differentiating MEL cells. 15 $\mu$ g of total RNA isolated from untreated or HMBA-treated MEL cells were hybridized with the electroeluted insert of pMH3A-3' containing the 3' noncoding region of a mouse $\mathrm{H} 3.3 \mathrm{~A}$ gene.

constitutively at a low rate throughout the cell cycle (17). Like other replacement histone variant genes, the $\mathrm{H} 3.3$ gene contains introns, produces polyadenylated mRNA and contains a long $3^{\prime}$ noncoding region $(18,25)$. All these characteristics are absent in replication-dependent histone genes. In mice, there are two types of $\mathrm{H} 3.3$ gene, $\mathrm{H} 3.3 \mathrm{~A}$ and H3.3B. Both genes code for the same protein but they differ extensively in their $5^{\prime}$ and $3^{\prime}$ noncoding regions $(20,24)$.

The $4.2 \mathrm{cDNA}$ clone isolated here by differential hybridization corresponds to the H3.3B type, as deduced by sequence analysis.
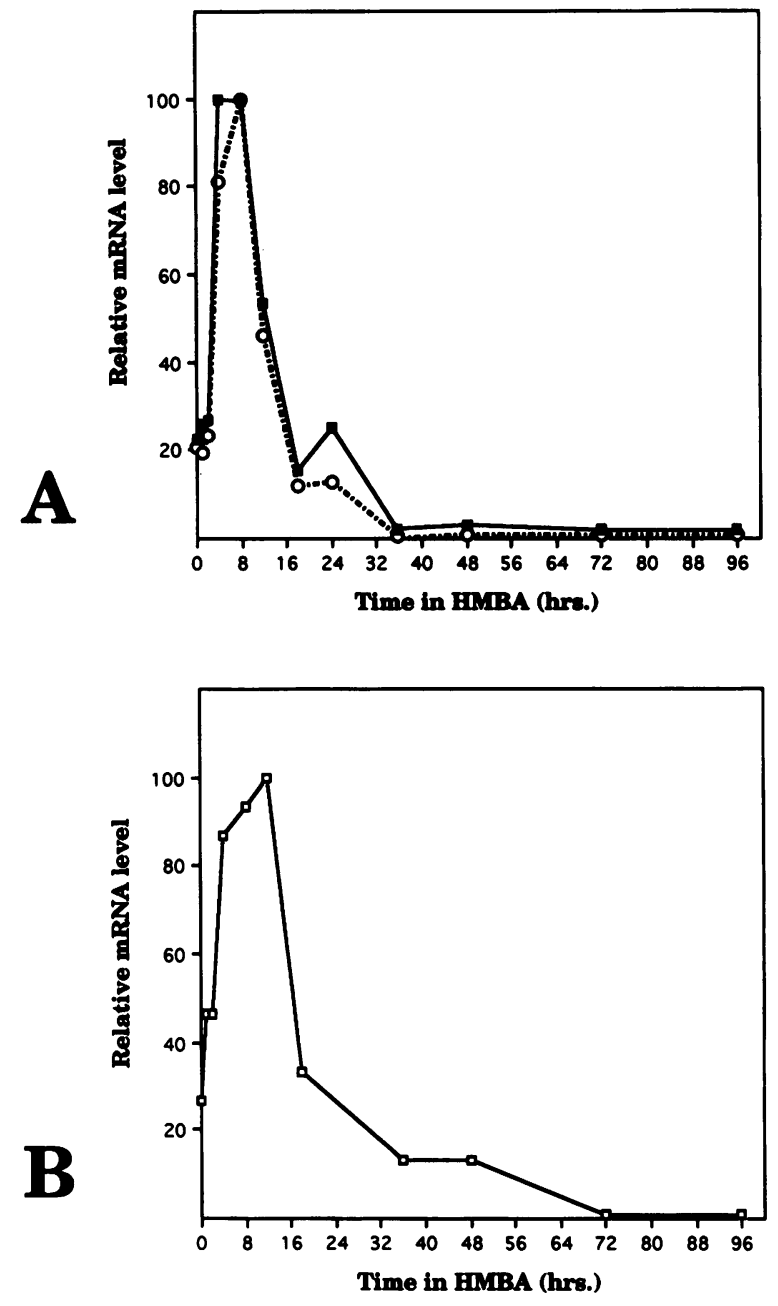

Figure 5. Relative levels of H3.3B and H3.3A mRNAs in differentiating MEL cells. The relative mRNA level during HMBA treament was quantitated by densitometric scanning of the autoradiograms shown in Figures 3a and 4. For each mRNA species the highest level obtained was normalized to 100 per cent. A: H3.3B mRNAs, $-\square-1.8 \mathrm{~kb}$ mRNA; $-\mathrm{O}-1.2 \mathrm{~kb}+1.0 \mathrm{~kb}$ mRNAs. The relative levels of the $1.2 \mathrm{~kb}$ and $1.0 \mathrm{~kb} \mathrm{H} 3.3 \mathrm{~B}$ mRNAs were combined since they were not fully resolved upon densitometric scanning of the autoradiogram. B: H3.3A mRNA, $-\square-1.2 \mathrm{~kb}$.

The $800 \mathrm{bp}$ insert in clone 4.2 contains a sequence which is identical to a previously reported mouse H3.3B cDNA from positions -60 to +759 of the published sequence (20). To determine which of the four RNA bands that hybridized with the 4.2 cDNA clone were specific for the H3.3B gene, we hybridized MEL cell RNA with a plasmid, designated pMH3B-3', which contains only the 3' noncoding region of the H3.3B gene (Figure 3a). Among the four RNA species that hybridized with the 4.2 cDNA clone only the $1.8,1.2$ and 1.0 $\mathrm{kb}$ species hybridized with the $3^{\prime}$ noncoding region probe. This observation agrees with previous results obtained in mouse kidney cells in which it was shown that the H3.3B gene produces three mRNAs differing in the lengths of the $3^{\prime}$ noncoding region due to use of three polyadenylation signals (20). To confirm that the three RNA species observed in Figure 3a corresponded to the three putative $\mathrm{H} 3.3 \mathrm{~B}$ poly $\mathrm{A}+\mathrm{mRNAs}$, we probed a similar filter with a 20-bp oligomer whose sequence is derived from the 


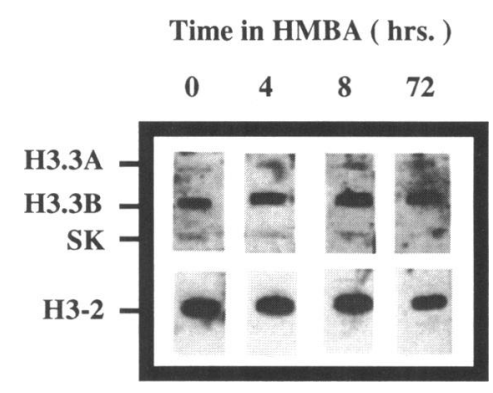

Figure 6. Nuclear run-on transcription in untreated and HMBA-treated MEL cells. ${ }^{32} \mathrm{P}$-labelled run-on RNA from isolated nuclei of untreated MEL cells ( 0 ) or cells treated with HMBA for 4,8 or 72 hrs. was hybridized with $10 \mathrm{mg}$ of the indicated plasmid DNAs immobilized on nitrocellulose strips: pMH3A-3' (H3.3A), pMH3B-3' (H3.3B), pSK vector (SK) and pRAH3-2 (H3-2) DNA. Hybridization with pRAH3-2 DNA was performed in separate reactions to avoid the possibility of competition for $\mathrm{H} 3.3$ transcripts.

sequence lying just after the termination codon of H3.3B, and obtained similar results (Figure 3b). Both probes (Figures 3a and $3 \mathrm{~b})$ showed that the amounts of the three H3.3B mRNAs increase after 2-4 hours of HMBA treatment. Beginning at about 8 hours of HMBA treatment the amount of the three RNA species declined such that they were present only at very low levels by the time differentiation was completed at about 96 hours. The smaller $0.6 \mathrm{~kb}$ RNA that was detected only with the $4.2 \mathrm{cDNA}$ clone was probably the result of cross-hybridization with replication-dependent $\mathrm{H} 3$ mRNAs. This was confirmed by showing that the $0.6 \mathrm{~kb}$ RNA hybridized with a probe containing a portion of the coding region of a mouse replication-dependent H3.2 gene (data not shown). It should be noted that the level of the $0.6 \mathrm{~kb} \mathrm{H} 3 \mathrm{mRNA}$ remains relatively constant during the early stages of HMBA treatment, indicating that induction of the three H3.3B mRNAs is not a general feature of $\mathrm{H} 3$ histone mRNAs.

The observed rapid increase in the steady state level of the H3.3B histone mRNAs during MEL cell differentiation led us to ask whether the H3.3A type histone also follows the same pattern. To investigate this possibility, we probed RNA blots with a KpnI-HindIII fragment derived from the $3^{\prime}$ noncoding region of a $\mathrm{H} 3.3 \mathrm{~A}$ gene (24). Northern blot hybridization showed a single RNA band of about $1.2 \mathrm{~kb}$ indicating that this probe did not hybridize with other $\mathrm{H} 3 \mathrm{mRNAs}$ (Figure 4). Like the H3.3B mRNAs, the H3.3A mRNA also increased by 4 hours of HMBA treatment and subsequently decreased.

The relative change in the level of each of the H3.3 mRNAs during differentiation was quantitated by densitometric scanning of the autoradiograms shown in Figures $3 \mathrm{a}$ and 4 . The results (Figure 5). show that the three H3.3B mRNAs as well as the H3.3A mRNA are coordinately induced 4-5 fold during the first few hours of HMBA treatment, reaching a maximum level between 4 and 12 hours. Thereafter the levels of all of the mRNAs decline rapidly to preinduced levels by $18-24$ hours and then decline futher to very low levels as the cells undergo differentiation.

To determine whether the induction of $\mathrm{H} 3.3 \mathrm{~A}$ and $\mathrm{H} 3.3 \mathrm{~B}$ mRNAs following HMBA treatment was due to increased transcription we carried out in vitro run-on transcription reactions in nuclei isolated from cells treated with HMBA for various

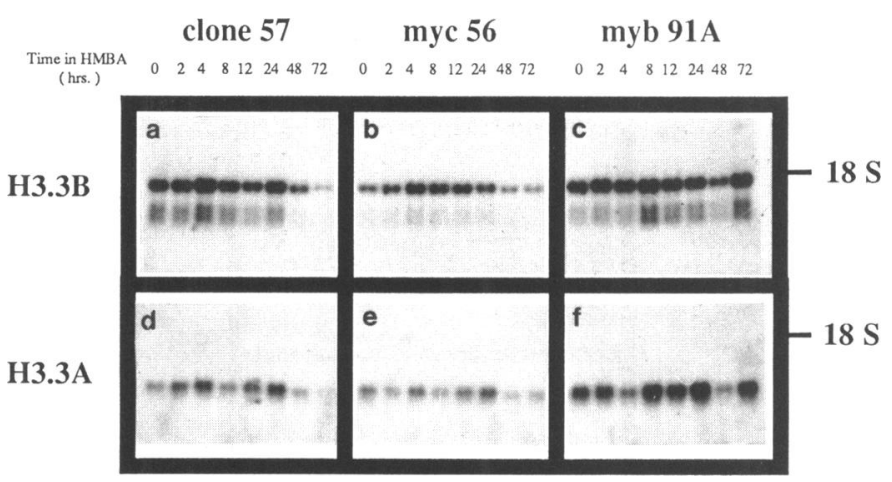

Figure 7. Analysis of H3.3 mRNA levels during HMBA treatment of deregulated c-myc and c-myb transfectants. MEL cell transfectants, clone 57 (panels a and d), myc 56 (panels b and e) and myb 91A (panels $c$ and f) were grown in the presence of $5 \mathrm{mM}$ HMBA. At the times indicated, total cellular RNA was isolated and analyzed by blot hybridization. Panels $\mathrm{a}, \mathrm{b}$ and $\mathrm{c}$ were hybridized with the electroeluted Eco RI fragment of the pMH3B-3' plasmid containing the 3' noncoding region of the H3.3B cDNA clone. Panels $d$, $e$ and $f$ were hybridized with the electroeluted Kpn I-Hind III fragment of pMH3A-3' containing the $3^{\prime}$ noncoding region of the H3.3A genomic pseudogene. After 5 days of HMBA treatment clone 57 produced $85 \%$ benzidine-positive cells, whereas clones myc 56 and myb $91 \mathrm{~A}$ produced less than $1 \%$ and $5 \%$ positive cells, respectively.

periods of time. The in vitro elongated RNA products were hybridized to immobilized probes derived from the 3 ' noncoding regions of both genes. A coding region probe derived from a H3.2 replication-dependent gene (23) was used as a control in separate hybridization reactions. We observed a small increase in the rate of $\mathrm{H3} .3 \mathrm{~B}$ transcription in nuclei from cells treated with HMBA for 4 and 8 hours (Figure 6). The increase is not sufficient however to account for the 4-5 fold induction in the steady-state level of the H3.3B mRNAs. Likewise, the rate of H3.3B transcription remained relatively high after 72 hours of HMBA treatment, despite the low level of $\mathrm{H} 3.3 \mathrm{~B}$ mRNA present in cells at this time (Figures 3 and 5). We conclude that both the induction and subsequent decline of H3.3B mRNA during MEL cell differentiation is primarily due to post-transcriptional control. Consistent with the lower levels of H3.3A mRNA compared with H3.3B mRNA in MEL cells and tissues (Figures $3,4,7)$ we were unable to detect significant levels of transcription of H3.3A.

Expression of H3.3A and H3.3B genes in deregulated c-myc and c-myb MEL transfectants

The level of expression of the c-myc and c-myb protooncogenes changes dramatically during the precommitment period of MEL cell differentiation. The amount of the mRNAs for both genes declines rapidly in the first hours after treatment of the cells with differentiation inducing agents and then returns to pretreatment levels at about 18-24 hours. We have shown previously that two polyadenylated $\mathrm{H} 1$ histone mRNAs are rapidly induced in this period. Furthermore, by studying MEL cell transfectants that are inhibited for differentiation due to overexpression of myc or myb from heterologous promoters we showed that induction of both $\mathrm{H} 1 \mathrm{mRNAs}$ is blocked specifically by overexpression of myc (11). Since the H3.3 mRNAs are also induced in this period we sought to determine whether their induction was affected by the level of expression of the protooncogenes.

We analyzed expression of $\mathrm{H} 3.3 \mathrm{~A}$ and $\mathrm{H} 3.3 \mathrm{~B}$ mRNAs in two 


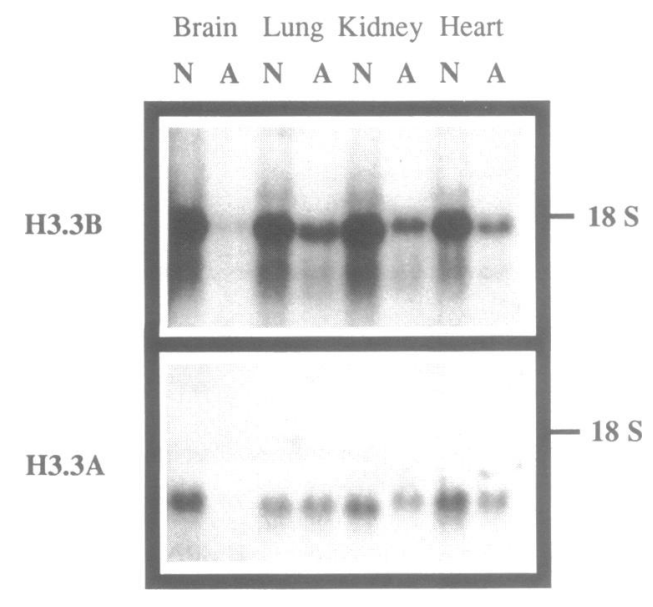

Figure 8. Northern blot hybridization of H3.3B and H3.3A mRNAs in newborn and adult mouse tissues. Fifteen micrograms of total RNA prepared from the indicated tissues were probed with radiolabeled fragments of pMHB-3' (H3.3B) and pMH3A-3' (H3.3A) plasmids. Hybridization was performed as described in Figure 6. $\mathrm{N}=$ newborn; $\mathrm{A}=$ two-months old $\mathrm{B} 6 / \mathrm{CBA}$ mice. The position of the 18S rRNA marker, visualized in the gel by ethidium bromide staining, is indicated at the right.

MEL transfectant cell lines, myc 56 (9) and myb 91A (13), that produce high levels of exogenous myc or myb transcripts respectively, and in a control transfectant cell line (clone 57, (9)) that contains only the SVneo selectable marker gene. The mRNA levels of $\mathrm{H} 3.3 \mathrm{~B}$ and $\mathrm{H} 3.3 \mathrm{~A}$ were observed to increase at early times of HMBA treatment in all three cell lines (Figure 7). Nevertheless, certain differences among these cell lines were apparent in the pattern of expression of both H3.3 genes. Firstly, although both types of mRNA were induced in the mycoverexpressing line, the level of the three H3.3B mRNAs as well as the $\mathrm{H} 3.3 \mathrm{~A}$ mRNA at all times were substantially reduced in this line when compared to that in the control and myboverexpressing lines. Secondly, while all H3.3B and H3.3A mRNAs were markedly down regulated after prolonged HMBA treatment of the control and myc transfected lines, as well as DS19 MEL cells (Figure 3), they remained at a high level in the myb overexpressing line. Thus, unlike the rapid induction of the H1 histone poly A+ mRNAs which is blocked by overexpression of myc (11), induction of H3.3 mRNAs appears to be unaffected by overexpression of either myc or myb. However, it may be that myb overexpression does affect the final down regulation of $\mathrm{H} 3.3 \mathrm{mRNAs}$ occurring in the late stages of MEL cell differentiation.

Expression of $\mathrm{H3.3}$ variant genes in different newborn and adult mouse tissues

H3.3 protein is a minor component of the chromatin in dividing cells but can become relatively abundant in nondividing adult tissues $(17,26)$. We investigated the expression at the level of mRNA of both H3.3A and H3.3B in newborn and adult mouse tissues to compare the patterns of expression at the two different developmental stages in several tissues. The results showed that both $\mathrm{H} 3.3 \mathrm{~A}$ and $\mathrm{H} 3.3 \mathrm{~B}$ genes were expressed in all tissues analyzed (Figure 8). With one exception the amount of the three H3.3B mRNAs and H3.3A mRNA however, was much higher in the newborn tissues. The brain constituted the most dramatic example of down regulation where both $\mathrm{H} 3.3 \mathrm{~A}$ and $\mathrm{H} 3.3 \mathrm{~B}$ mRNAs reached barely detectable levels in adults. The one exception was the lung in which the level of H3.3A mRNA was approximately the same in newborns and adults.

\section{DISCUSSION}

Mouse erythroleukemia cell lines represent a well studied model for the switching of tumor cells into a terminal differentiation program. Reinitiation of the erythroid differentiation program in MEL cells by chemical inducers such as HMBA is thought to occur in two distinct phases. During the first phase, the precommitment period, lasting 12-24 hours, withdrawal of inducer allows the cells to return to the uncontrolled proliferative state characteristic of the MEL tumor cell line. Once cells have committed, however, they are irreversibly programmed to complete erythroid differentiation, including accumulation of hemoglobin and other red cell-specifc markers as well as terminal cell division (2). To understand the events leading to the committed state we and others have sought to identify genes that change their expression during the precommitment period. A number of genes are now known to be rapidly down-regulated in the first few hours after treating MEL cells with differentiationinducing agents. They include c-myc, c-myb and p53 $(7,8)$ as well as Id-1 and Spi-1 (PU-1) (G. C. and AIS, unpublished observations), the ets family member gene near which the spleenfocus forming virus SFFV integrates in many mouse erythroleukemias. Likewise, several genes have been described to be rapidly up-regulated during the precommitment period. They include c-fos (7) and two $\mathrm{H} 1$ histone genes, $\mathrm{H}^{\circ}$ and H1 var.1, that encode polyadenylated mRNAs (11). Important questions regarding these gene expression changes are whether they represent a cascade of interrelated events and whether they affect the differentiation program. A number of studies have shown that deregulated expression of c-myc or c-myb interferes with MEL cell differentiation $(9,10,13,14,15,16)$. Our finding that the rapid induction of the two $\mathrm{H} 1$ histone mRNAs is inhibited by c-myc but not by c-myb supports the notion of a gene expression cascade and further indicates that c-myc and c-myb play independent roles in the MEL cell differentiation program.

To identify additional genes that are induced during the precommitment period we used differential hybridization to probe a cDNA library made from MEL cells induced to a point just prior to the time when the cells begin to commit to terminal differentiation. When properly controlled the differential hybridization technique is ideally suited for identifying even relatively small changes in gene expression, although it is limited to the detection of relatively abundant sequences. By using quadruplicate filter lifts of phage cDNA libraries plated at low density (about 700 plaques $/ 150 \mathrm{~mm}$ plate) we have been able to identify mRNA sequences exhibiting $4-5$ fold changes in abundance (Figs 2 and 3 and G.Rao, DBK and AIS, in preparation). Several of the genes shown previously to change expression in the precommitment period, including c-myc and c-myb, exhibit quantitative changes in mRNA level of 5-15 fold, which might not be detected using subtractive hybridization methods.

One of the cDNAs we isolated by differential hybridization corresponds to the $\mathrm{H} 3.3 \mathrm{~B}$ gene as deduced by sequence analysis of the $3^{\prime}$ untranslated region. Confirming previous results (20) we found that the $\mathrm{H} 3.3 \mathrm{~B}$ gene encodes three polyadenylated 
mRNAs differing in the lengths of the $3^{\prime}$ noncoding region. The three mRNAs are coordinately induced during the first few hours of HMBA treatment, achieving a maximum level between 4 and 12 hours. Thereafter the mRNA levels return to preinduction levels and gradually decrease as the cells undergo terminal differentiation. Nuclear run-on transcription experiments failed to detect substantial changes in the rate of transcription of the $\mathrm{H} 3.3 \mathrm{~B}$ gene throughout this period, suggesting that both the initial accumulation of the H3.3B mRNAs and their subsequent decline are governed by post-transcriptional mechanisms. Using a $3^{\prime}$ noncoding region probe specific for the $\mathrm{H} 3.3 \mathrm{~A}$ gene we detected a single mRNA species. The H3.3A mRNA exhibited a very similar pattern of accumulation and decline as seen for the three $\mathrm{H} 3.3 \mathrm{~B}$ mRNAs. The transcription of the H3.3A gene in isolated nuclei was too low to make an accurate determination as to whether its rate of transcription changes. Nevertheless the very similar kinetics of increase and decrease for the four H3.3 mRNA species suggests a coordinate regulation, probably at the level of post-transcriptional control. Brown, et al., (27) previously reported that the steady state level of a H3.3 mRNA was relatively constant in MEL cells after HMBA treatment. However these authors did not study the mRNA level prior to 24 hours of HMBA treatment.

We have described previously two other histone genes which encode polyadenylated $\mathrm{H} 1$ histone mRNAs that are induced during the precommitment period in MEL cells (11). Both H1 genes produce two mRNAs, one of which in each case exhibits a pattern of induction and decline very similar to that shown here for the H3.3A and H3.3B mRNAs. The H1var. 1 gene produces two mRNAs, a nonpolyadenylated, cell cycle regulated mRNA and a polyadenylated, replication-independent mRNA. Only the latter form is induced in the first few hours after treating MEL cells with HMBA and the kinetics of induction and decline of this mRNA are very similar to that reported here for the $\mathrm{H} 3.3 \mathrm{~A}$ and H3.3B mRNAs (28). The $\mathrm{H} 1^{\circ}$ gene also produces two mRNAs, a $1.0 \mathrm{~kb}$ mRNA and a $2.2 \mathrm{~kb}$ mRNA both of which are polyadenylated. Interestingly the $1.0 \mathrm{~kb} \mathrm{H} 1^{\circ} \mathrm{mRNA}$ is rapidly induced after HMBA treatment and then declines after 8-12 hours of HMBA treatment, whereas the $2.2 \mathrm{~kb} \mathrm{H} 1^{\circ}$ mRNA is also rapidly induced but is maintained at a high level throughout the differentiation program (29). The observation that several different polyadenylated histone mRNAs are induced and then down-regulated during the MEL cell precommitment period could suggest that there is a common control mechanism operating specifically on this unique class of mRNAs. However, two types of observations argue against this possibility. Firstly, control of the two H1 histone genes occurs via increased transcription (29), whereas the induction and down-regulation of the $\mathrm{H} 3.3 \mathrm{~A}$ and H3.3B genes appears to be controlled primarily by a posttranscriptional mechanism. Secondly, whereas induction of the $\mathrm{H} 1 \mathrm{var} .1$ and $\mathrm{H} 1^{\circ}$ polyadenylated mRNAs is blocked specifically by deregulated expression of c-myc (11), using the same transfected cell lines used previously for studying the $\mathrm{H} 1$ genes we did not find an effect of deregulated expression of c-myc or c-myb on the induction of H3.3A and H3.3B mRNAs. However it is worth noting that overexpression of myb did appear to inhibit the down regulation of $\mathrm{H} 3.3 \mathrm{~A}$ and $\mathrm{H} 3.3 \mathrm{~B}$ mRNAs occurring in control and myc overexpression lines after prolonged treatment with HMBA (Figure 6). Further study of additional myb transfected cell lines will be needed to confirm this point.

In summary, we have found that the polyadenylated mRNAs produced from four different histone genes are rapidly induced and then down-regulated during the precommitment period of MEL cell differentiation. Different control mechanisms appear to be responsible for the observed changes in mRNA levels, at least for the $\mathrm{H} 1$ vs $\mathrm{H} 3.3$ genes, involving separate transcriptional and post-transcriptional steps. Future studies of these changes in gene expression should help to elucidate the cascade of events that cause the MEL tumor lines to switch into their terminal differentiation program.

\section{ACKNOWLEDGEMENTS}

This work was supported by National Institutes of Health Grant CA 16368 and an Albert Einstein College of Medicine Cancer Core Grant (NIH 2P30 CA 13330). D.K. received support from the C.E., Comunidad de Madrid.

\section{REFERENCES}

1. Friend, C., Scher, W., Holland, J. and Sato, T. (1971) Proc. Natl. Acad. Sci. USA, 68, 378-382.

2. Marks, P.A. and Rifkind, R.A. (1978) Ann. Rev. Biochem., 47, 419-448.

3. Marks, P., Ramsay, R., Sheffery, M. and Rifkind, R. (1987) In Developmental Control of Globin Gene Expression, pp. 253-268 Alan R. Liss, Inc., New York.

4. Gusella, J., Geller, R., Clarke, B., Weeks, V. and Housman, D. (1976) Cell, 9, 221-229.

5. Profous-Juchelka, H.R., Reuben, R.C., Marks, P.A. and Rifkind, R.A. (1983) Mol. Cell.Biol. 3, 229-232.

6. Ganguly, S. and Skoultchi, A.I. (1985) J. Biol. Chem., 260, 12167-12173.

7. Ramsay, R.G., Ikeda, K., Rifkind, R.A. and Marks, P.A. (1986) Proc. Natl. Acad. Sci. USA, 83, 6849-6853.

8. Lachman, H.M. and Skoultchi, A.I. (1984) Nature, 130, 592-594.

9. Dmitrovsky, E., Kuehl, W.M., Hollis, G., Kirsch, I.K., Bender, T.P. and Segal, S. (1986) Nature,322, 748-750.

10. Lachman, H.M., Cheng, G. and Skoultchi, A.I. (1986) Proc. Natl. Acad.Sci. USA, 83, 6480-6484.

11. Cheng, G. and Skoultchi, A.I. (1989) Molec. Cell.Biol. 9, 2332-2340.

12. Chen, Z., Banks, J., Rifkind, R.A. and Marks, P.A. (1982) Proc. Natl. Acad. Sci.USA, 79, 471-475.

13. Clarke, M.F., Kukowska-Latallo, J.F., Westin, E., Smith, M. and Prochownik, E.V. (1988) Mol. Cell. Biol.,.8, 884-892.

14. Coppola, J.A. and Cole, M.D. (1986) Nature, 320, 760-763.

15. Kume, T., Takada, S. and Obinata, M. (1988) J. Mol. Biol., 202, 779-786.

16. Prochownik, E.V. and Kukowska, J. (1986) Nature, 322, 848-850.

17. Zweidler, A. (1984) In Core histone variants of the mouse: Primary structure and differential expression., pp. 339-371. Wiley, New York.

18. Brush, D., Dodson, J., Choi, O., Stevens, P. and Engel, J. (1985) Molec. Cell. Biol., 5, 1307-1317

19. Chalmers, M. and Wells, D. (1990) Nucleic Acids Res.,18, 3075.

20. Hraba-Renevey, S. and Kress, M. (1989) Nucleic Acids Res., 17, 2449-2461.

21. Benton, D. and Davis, R.W. (1977) Science,196, 180-182.

22. Soeiro, R. and Darnell, J.E. (1969) J. Mol. Biol., 44, 551-562.

23. Alterman, R.M., Sprecher, C., Graves, R., Marzluff, W.F. and Skoultchi, A.I. (1985) Molec. Cell. Biol., 5, 2316-2324.

24. Wellman, S.E., Casano, P.J., Pilch, D.R., Marzluff, W.F. and Sittman, D.B. (1987) Gene, 59, 29-39.

25. Wells, D. and Kedes, L. (1985) Proc. Natl. Acad. Sci. USA, 82, 2834-2838.

26. Gabrielli, F., Aden, D., Carrel, S., Bahr, C.v., Rane, A., Angeletti, C. and Hancock, R. (1985) Molec. Cell. Biochem., 65, 57-66.

27. Brown, D., Wellman, S. and Sittman, D. (1985) Molec. Cell. Biol., 5, 2879-2886.

28. Cheng, G., Nandi, A., Clerk, S. and Skoultchi, A. (1989) Proc. Natl.. Acad. Sci. USA, 86, 7002-7006.

29. Cheng, G. (1989) Ph.D. Dissertation, Albert Einstein College of Medicine. 